\title{
A $\beta$ Hinders Nuclear Targeting of AICD and Fe65 in Primary Neuronal Cultures
}

\author{
A. G. Henriques - S. I. Vieira • E. F. da Cruz e Silva • \\ O. A. B. da Cruz e Silva
}

Received: 17 October 2008 / Accepted: 19 January 2009/Published online: 2 April 2009

(C) Humana Press 2009

\begin{abstract}
The intracellular domain of the Alzheimer's amyloid precursor protein (AICD) has been described as an important player in the transactivation of specific genes. It results from proteolytic processing of the Alzheimer's amyloid precursor protein (APP), as does the neurotoxic $A \beta$ peptide. Although normally produced in cells, $A \beta$ is typically considered to be a neurotoxic peptide, causing devastating effects. By exposing primary neuronal cultures to relatively low $A \beta$ concentrations, this peptide was shown to affect APP processing. Our findings indicate that APP C-terminal fragments are increased with concomitant reduction in the expression levels of APP itself. AICD nuclear immunoreactivity detected under control conditions was dramatically reduced in response to $A \beta$ exposure. Additionally, intracellular protein levels of Fe65 and GSK3 were also decreased in response to A $\beta$. APP nuclear signaling is altered by $A \beta$, affecting not only AICD production but also its nuclear translocation and complex formation with $\mathrm{Fe} 65$. In effect, $\mathrm{A} \beta$ can trigger a physiological negative feedback mechanism that modulates its own production.
\end{abstract}

Keywords A $\beta$ peptide $\cdot$ APP RIP signaling .

Alzheimer's disease $\cdot \mathrm{Fe} 65 \cdot \mathrm{CTFs} \cdot \mathrm{AICD}$

\footnotetext{
A. G. Henriques · S. I. Vieira • O. A. B. da Cruz e Silva $(\triangle)$ Laboratório de Neurociências, Centro de Biologia Celular, SACS, Universidade de Aveiro,

Campus de Santiago,

Aveiro, Portugal

e-mail: odetecs@ua.pt

E. F. da Cruz e Silva

Laboratório de Transdução de Sinais, Centro de Biologia Celular, Universidade de Aveiro,

Aveiro, Portugal
}

\section{Introduction}

$A \beta$ was originally defined as a pathogenic peptide associated with Alzheimer's disease (AD), but it is now known to be produced during normal intracellular processing of the Alzheimer's amyloid precursor protein (APP; Haass et al. 1992, 1993; Selkoe 1993; da Cruz e Silva et al. 2004). Consecutive APP cleavage by $\alpha$-secretase (Sisodia 1992; Buxbaum et al. 1998; Allinson et al. 2003) and the $\gamma$ secretase complex (Li et al. 2000; Sastre et al. 2001; Esler et al. 2002; Lee et al. 2002; Capell et al. 2005) precludes $\mathrm{A} \beta$ production and produces a smaller fragment termed $\mathrm{P} 3$, whereas cleavage by $\beta$-secretase and $\gamma$-secretase results in the production of $A \beta$ peptides, mainly in Golgi and endosomes (Vassar et al. 1999; Yan et al. 2001; Rebelo et al. 2007). The former non-amyloidogenic cleavage pathway also leads to the production of $\operatorname{sAPP} \alpha$, while the latter results in $\mathrm{SAPP} \beta$ production. Proteolytic SAPP products are typically secreted, although intracellular sAPP (isAPP) production has been detected (Carlson et al. 2000; Henriques et al. 2009). Resulting APP C-terminal fragments (CTFs), the products of $\alpha$ - and $\beta$-secretase activities, may be cleaved by $\gamma$-secretase at $\gamma$ - and $\varepsilon$-sites, giving rise to the APP intracellular domain (AICD; Sastre et al. 2001). Cao and Sudhof (2001) have shown that AICD exhibits transcriptional activity, enhanced by the formation of a transcriptional active complex comprising AICD, Fe65, and the histone acetylase Tip60. This trimeric complex was reported to localize to multiple spherical nuclear compartments (von Rotz et al. 2004). AICD and Fe65 localize together at the nucleus (Kimberly et al. 2001; Minopoli et al. 2001; Walsh et al. 2003), and nuclear AICD-containing complexes were reported to activate the transcription of several genes, including APP itself, BACE, Tip60 (von Rotz et al. 2004), GSK3 $\beta$ (Kim et al. 2003; Ryan and Pimplikar 
2005), KAI1 (Baek et al. 2002), and Neprilysin (PardossiPiquard et al. 2005). However, it is still unclear how the translocation of Fe65 and AICD from the cytoplasm and/or membrane into the nucleus is accomplished.

APP/Fe65 interaction is also known to modulate APP metabolism, including sAPP secretion and A $\beta$ production (Sabo et al. 1999; Ando et al. 2001). Sabo et al. (1999) reported that in MDCK cells stably expressing $\mathrm{APP}_{695}$, Fe65 increased APP translocation to the plasma membrane, which was accompanied by an increase in $\mathrm{A} \beta$ and $\operatorname{sAPP} \alpha$ secretion. Recently, Xie et al. (2007) showed that Fe65 RNAi silencing leads to an increase in CTF levels and a decrease in $A \beta$ levels, thus suggesting a role for Fe65 as a positive regulator of $\gamma$-secretase activity.

The present work focuses on the effect of exogenously added A $\beta$ on APP metabolism in primary neuronal cultures and its effects on AICD/Fe65 nuclear signaling. The data obtained support the hypothesis that $\mathrm{A} \beta$ plays a role in APP processing and RIP signaling by altering APP intracellular proteolytic cleavage and by decreasing both APP and Fe65 intracellular and nuclear levels. The intracellular A $\beta$ effects appear to include decreased AICD production, given the increase in CTFs production and decreased targeting and nuclear co-localization of AICD/Fe65.

\section{Materials and Methods}

Preparation and Maintenance of Primary Neuronal Cultures

Rat cortical and hippocampal cultures were established from embryonic day 18 embryos as previously described (Henriques et al. 2007). After dissociation with trypsin $(0.45$ or $0.75 \mathrm{mg} /$ $\mathrm{ml}$ for cortical or hippocampal cultures, respectively, for 5$10 \mathrm{~min}$ at $\left.37^{\circ} \mathrm{C}\right)$ and deoxyribonuclease $\mathrm{I}(0.15 \mathrm{mg} / \mathrm{ml})$ in Hank's balanced salt solution, cells were plated on poly-Dlysine-coated dishes at a density of $1.0 \times 10^{5}$ cells $/ \mathrm{cm}^{2}$ in B27supplemented Neurobasal medium (GIBCO), a serum-free medium combination (Brewer et al. 1993). The medium was supplemented with glutamine $(0.5 \mathrm{mM})$, gentamicin (60 $\mu \mathrm{g} / \mathrm{ml})$, and with or without glutamate $(25 \mu \mathrm{M})$ for hippocampal or cortical cultures, respectively. Cultures were maintained in an atmosphere of $5 \% \mathrm{CO}_{2}$ at $37^{\circ} \mathrm{C}$ for 9 days before being used for experimental procedures.

Incubation with $A \beta$ Peptide

$\mathrm{A} \beta_{25-35}$ peptide (Sigma Aldrich) was dissolved in distilled water to prepare a $1 \mathrm{mM}$ stock. Rat primary neuronal cultures were incubated for $24 \mathrm{~h}$ in Neurobasal medium free of B27 containing $20 \mu \mathrm{M} \mathrm{A} \beta_{25-35}$, with the medium being replaced during the last $3 \mathrm{~h}$ of incubation by fresh medium with or without $\mathrm{A} \beta_{25-35}$.
Sample Collection and Immunoblotting

Following exposure to $A \beta$, conditioned media and cells were collected in boiling 1\% sodium dodecyl sulfate (SDS) and the lysates were homogenized as previously described (Amador et al. 2004). Protein determination was carried out using the BCA kit (Pierce). Samples normalized for protein content were separated on $7.5 \%$ or $5-20 \%$ gradient SDS polyacrylamide gels and then electrophoretically transferred onto nitrocellulose membranes for immunoblotting. Intracellular APP/isAPP and extracellular sAPP detection was carried out using the 22C11 mouse monoclonal antibody directed against the APP $\mathrm{N}$ terminus (Boehringer), while for holoAPP and endogenous C-terminal fragments, an APP C-terminal antibody was used (rabbit polyclonal anti$\beta$-APP C terminus, Zymed). Detection of total GSK3 was achieved using a rabbit polyclonal anti-glycogen synthase kinase 3 antibody (Chemicon). For Fe65 detection, the antibody clone 3H6 (Uspstate) was used, and tubulin detection was carried out using the monoclonal anti- $\beta$ tubulin antibody (Zymed). Following incubation with the primary antibodies, immunodetection made use of horseradish peroxidase-conjugated anti-mouse or anti-rabbit IgGs secondary antibodies (Amersham Pharmacia), and for visualization, enhanced chemiluminescence detection (ECL) was employed (Amersham Pharmacia). The ECL Plus reagent was used for extracellular sAPP, CTFs, and Fe65 detection.

\section{Quantification}

Quantity One densitometry software (Bio-Rad) was used to quantify band intensity and correlate it to protein levels. Data are expressed as mean \pm SEM of at least three independent experiments. Statistical analysis was carried out using one-way analysis of variance. When significantly different, the Dunnett test was applied to compare all groups to the control. The level of statistical significance accepted was $P<0.05$.

\section{Northern Blot Analysis}

Total RNA was isolated from control primary cortical cultures $\left(3.0 \times 10^{6}\right.$ cells) following $A \beta$ treatment (TRI REAGENT, Sigma). Normalized total RNA aliquots $(10 \mu \mathrm{g})$ were separated by formaldehyde gel electrophoresis and transferred to nitrocellulose membranes using standard laboratory protocols (da Cruz e Silva et al. 2009). The blot was then hybridized with a $\left[{ }^{32} \mathrm{P}\right]$-labeled APP cDNA probe (25 ng, $1 \times 10^{6} \mathrm{cpm} / \mathrm{ng}$ ) to evaluate APP expression levels. The APP probe used (756 bp) was obtained by AgeI/BamHI restriction enzyme digestion of the $\mathrm{APP}_{751}$ cDNA and labeled with $\left[\alpha-{ }^{32} \mathrm{P}\right] \mathrm{dCTP}$ (GE Healthcare) using the High 
Prime DNA labeling kit (Roche, Alfagene). Purification of the probe through NucTrap Probe purification columns (Stratagene, Alfagene) was performed prior to hybridization. APP hybridizing RNA was detected using Kodak Biomax XAR film (Sigma).

Monitoring Nuclear Targeting of APP C-Terminal Proteolytic Products

For evaluating nuclear targeting of APP C-terminal proteolytic products and Fe65, cells were fixed with 4\% paraformaldehyde, permeabilized with methanol for $2 \mathrm{~min}$, and blocked with $3 \%$ bovine serum albumin in phosphate-buffered saline (PBS) for $1 \mathrm{~h}$ and further incubated with primary antibody (C-terminal APP antibody and Fe65 antibody) for $3 \mathrm{~h}$. The antibody 4G8 (anti-Abeta 17-24 aa antibody, Chemicon) was used in colocalization studies with the APP C-terminal antibody to rule out nuclear CTFs and confirm the identity of AICD at the nucleus. After washing with PBS, Texas Red-conjugated goat anti-rabbit (Molecular Probes) or fluorescein-conjugated goat anti-mouse (Calbiochem) secondary antibodies were added for $2 \mathrm{~h}$ at room temperature. Coverslips were mounted on microscope glass slides using FluoroGuard (BioRad) as an antifading reagent or Vectashield (Vector Laboratories), an antifading reagent containing 4',6-diamidino-2-phenylindole (DAPI) for nucleic acid labeling. Nuclear targeting and colocalization studies of APP C-terminal fragments and Fe65 was carried out by immunofluorescence analysis. Acquisition of epifluorescence images made use of a LSM 510-Meta confocal microscope (Zeiss) and a $63 \times / 1.4$ oil immersion objective. The argon laser lines of $405 \mathrm{~nm}$ (DAPI), $488 \mathrm{~nm}$ (fluorescein), and a 561-nm DPSS laser (Texas Red) were used. Microphotographs were acquired in a sole section in the $z$-axis ( $x y$ mode) and represent a mean of 16 scans.

\section{Results and Discussion}

\section{A $\beta$ Affects APP Expression Levels}

A $\beta$ effects on APP metabolism are unclear, with some reports suggesting that $\mathrm{A} \beta$ may be affecting $A P P$ transcription, while others suggest it to have an effect at the APP processing/catabolic levels (Davis-Salinas et al. 1995; Schmitt et al. 1997; Carlson et al. 2000). In our work, primary neuronal cultures were incubated with and without $\mathrm{A} \beta_{25-35}$ during $24 \mathrm{~h}$ and total RNA extracted for Northern blot analysis (Fig. 1a). Although $\mathrm{A} \beta$ induction of $A P P$ transcription was previously reported in a neuronal hybrid cell line and in cultured astrocytes (Le et al. 1995; MorenoFlores et al. 1998), under our experimental conditions, A $\beta$ treatment lead to a clear decrease in $A P P$ expression in primary cortical cultures. Accordingly, APP intracellular

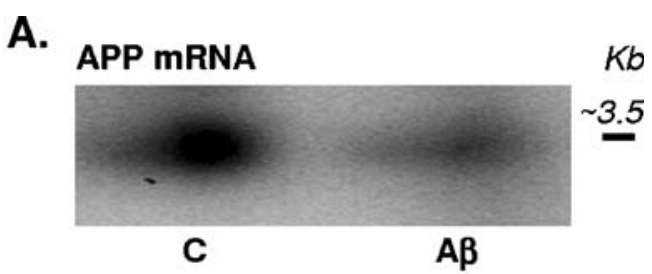

B.

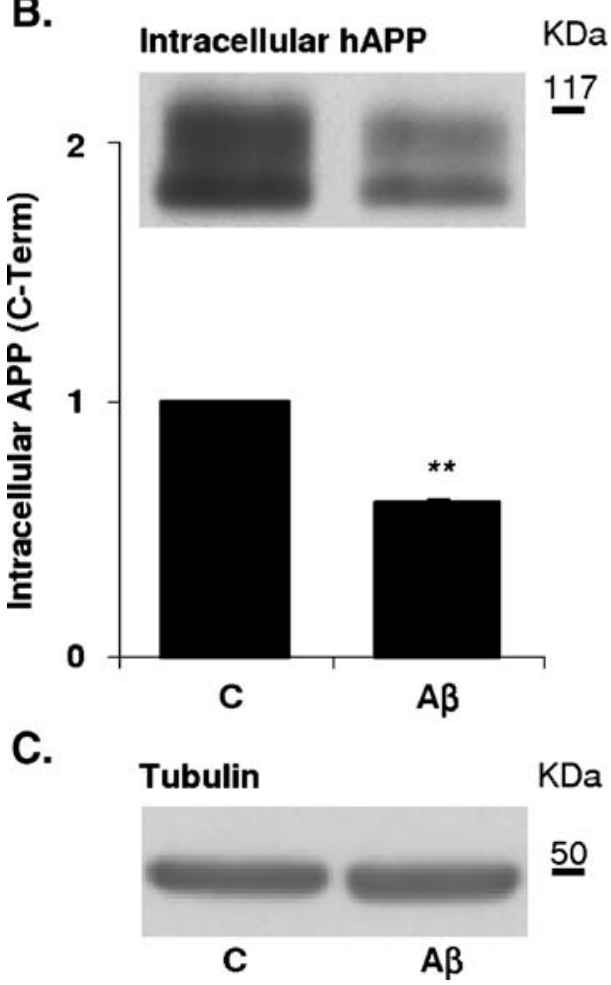

Figure $1 \mathrm{~A} \beta$ decreases $A P P$ expression in primary neuronal cultures. Primary cortical neuronal cultures were treated with $20 \mu \mathrm{M} \mathrm{A} \beta_{25-35}$ for $24 \mathrm{~h}$ as described in "Materials and Methods". a Total mRNA was isolated and APP mRNA expression in primary cultures was monitored in response to $A \beta$ exposure. b Intracellular holoAPP $(h A P P)$ protein detection was carried out using an antibody to the APP $\mathrm{C}$ terminus. c Tubulin was used as a control. $C$ control, $A \beta \mathrm{A} \beta$ treatment for 24 h. $* * P<0.01$, significantly different from control using Dunnett post hoc test

protein levels also dropped a concordant 0.4-fold below control levels upon $A \beta$ exposure (Fig. 1b). Similar results were obtained for hippocampal cultures, with $A \beta$ leading to a decrease in APP intracellular levels (as detected using an APP C-terminal antibody, Fig. 2a), again supporting a role for $\mathrm{A} \beta$ in modulating $A P P$ transcriptional levels in primary hippocampal cultures.

\section{A $\beta$ Induces Accumulation of APP C-Terminal Fragments}

Our data show that $A \beta_{25-35}$ provokes a decrease in intracellular holoAPP (hAPP, Fig. 2a), detected using the APP C-terminal antibody in primary neuronal cultures. Concomitantly, using the APP N-terminal antibody 22C11, 
A.

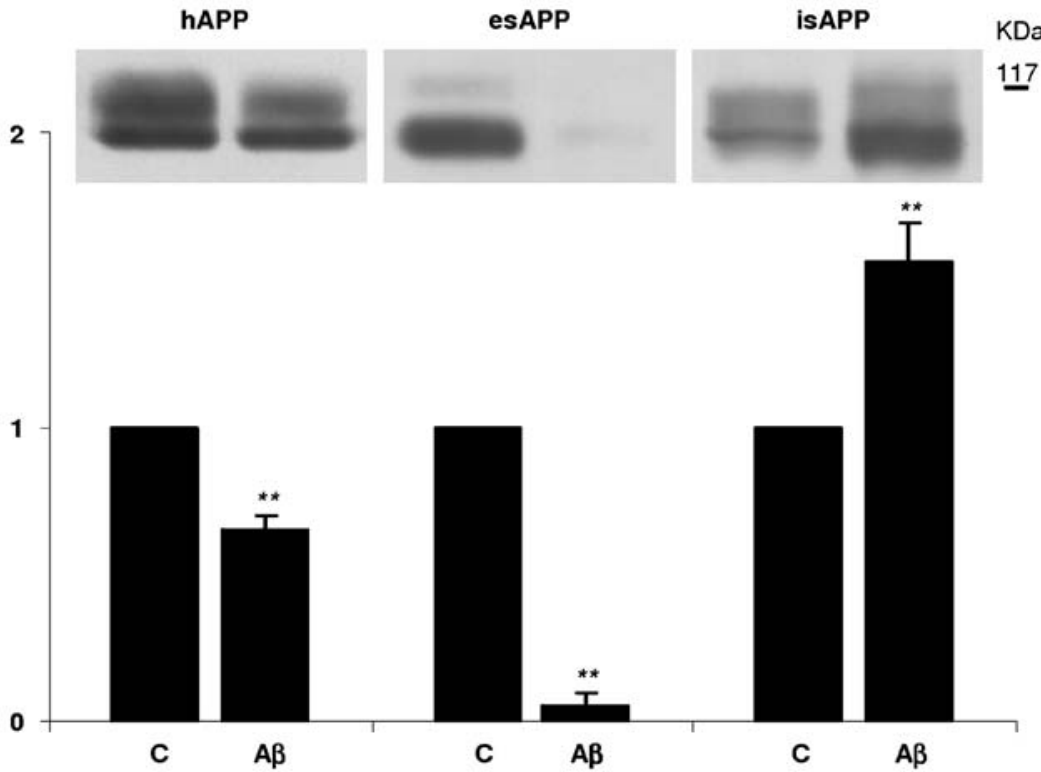

B.

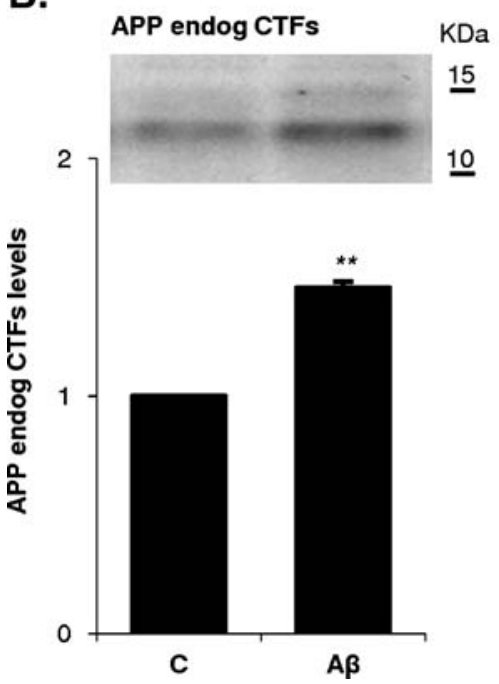

Figure 2 Effect of $\mathrm{A} \beta$ on $\mathrm{CTF}$ production. Following incubation of hippocampal neurons with $\mathrm{A} \beta$ peptide, cell lysates and conditioned medium were collected and analyzed. a Endogenous intracellular holoAPP $(h A P P)$, extracellular secreted sAPP (esAPP), and intracellular SAPP (isAPP). APP and sAPP were distinguished using the APP Cterminal antibody and the APP N-terminal antibody. b APP C-terminal

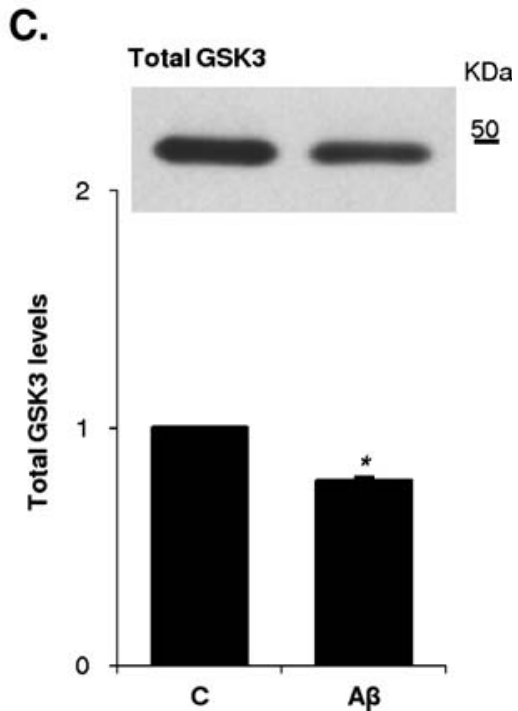

fragments $(A P P C T F s)$ were detected with an APP C-terminal antibody. c Total GSK3 expression levels. ${ }^{*} P<0.05$ and $* * P<0.01$, significantly different from control using Dunnett post hoc test. Values are expressed as mean $\pm \mathrm{SEM}$ from three independent experiments. $C$ control, $A \beta \mathrm{A} \beta$ treatment for $24 \mathrm{~h}$ we could observe a decrease in extracellular sAPP secretion (esAPP, Fig. 2a) and an increase in APP intracellular levels. The latter represents intracellularly accumulated sAPP (isAPP, Fig. 2a) since hAPP levels decreased. This isAPP retention was previously reported by us (Henriques et al. 2009 ) in various cell types, and $A \beta_{1-42}$ elicits a similar response. Retention of isAPP was also observed with the physiological $A \beta_{1-40}$ peptide (Carlson et al. 2000). In this case, increases in medium secreted proteins, such as IL-8, concomitant with decreases in sAPP secretion, by $10-30 \%$, were reported. Given that $\mathrm{A} \beta$ was clearly altering APP processing (Fig. 2), we monitored the levels of other APP proteolytic fragments and observed that these too were affected. The levels of endogenous CTFs produced by APP proteolytic processing increased with $\mathrm{A} \beta$ treatment (Fig. $2 b$ ). This suggests that $\gamma$-secretase activity was inhibited by $A \beta$ and/or that CTFs were not accessible for $\gamma$-secretase cleavage. However, direct measurement of $\gamma$-secretase 
Figure $3 \mathrm{~A} \beta$ induces alterations in AICD and Fe65 nuclear targeting. Hippocampal neuronal cultures were incubated with $A \beta_{25-35}$ for $24 \mathrm{~h}$ and subsequently fixed with paraformaldehyde. Immunofluorescence analyses were carried out using anti- $\beta$-APP $C$-terminal and anti-Fe65 antibodies, labeled with a Texas Redconjugated (red staining) or with a fluorescein-conjugated (green staining) antibody, respectively. Cells were mounted with an antifading reagent containing DAPI for nuclei acids staining. a AICD and Fe65 immunoreactivity was analyzed by confocal microscopy. b Representative profiles. Fluorescence intensity profiles represent the voxels through the white lines indicated in the merged image shown in a. c The identity of AICD fragments at the nucleus was shown by the positive immunoreactivity for the APP C-terminal antibody (Texas Redconjugated, red staining) and the negative immunoreactivity for the 4G8 antibody (fluorescein-conjugated, green staining). $C$ control, $A \beta \mathrm{A} \beta$ treatment for $24 \mathrm{~h}$
A.
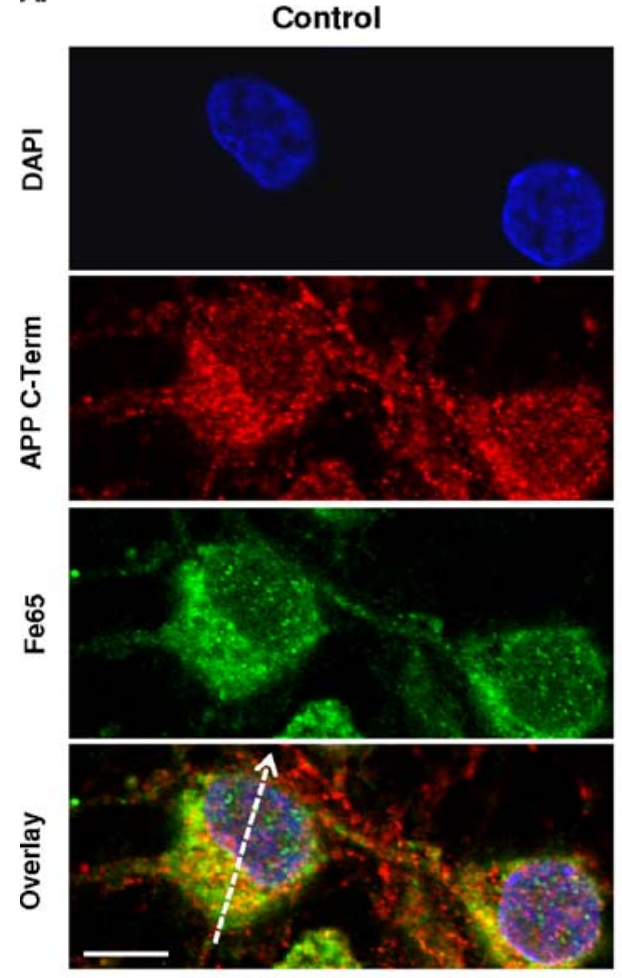

B.
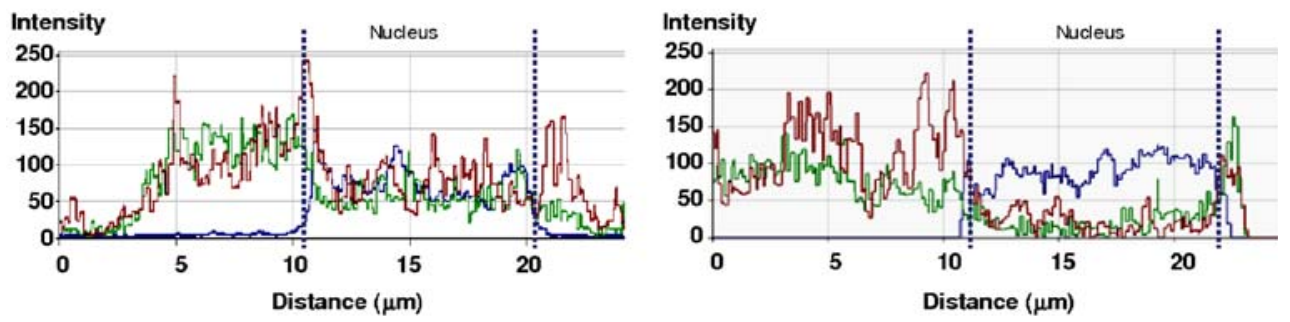

c.
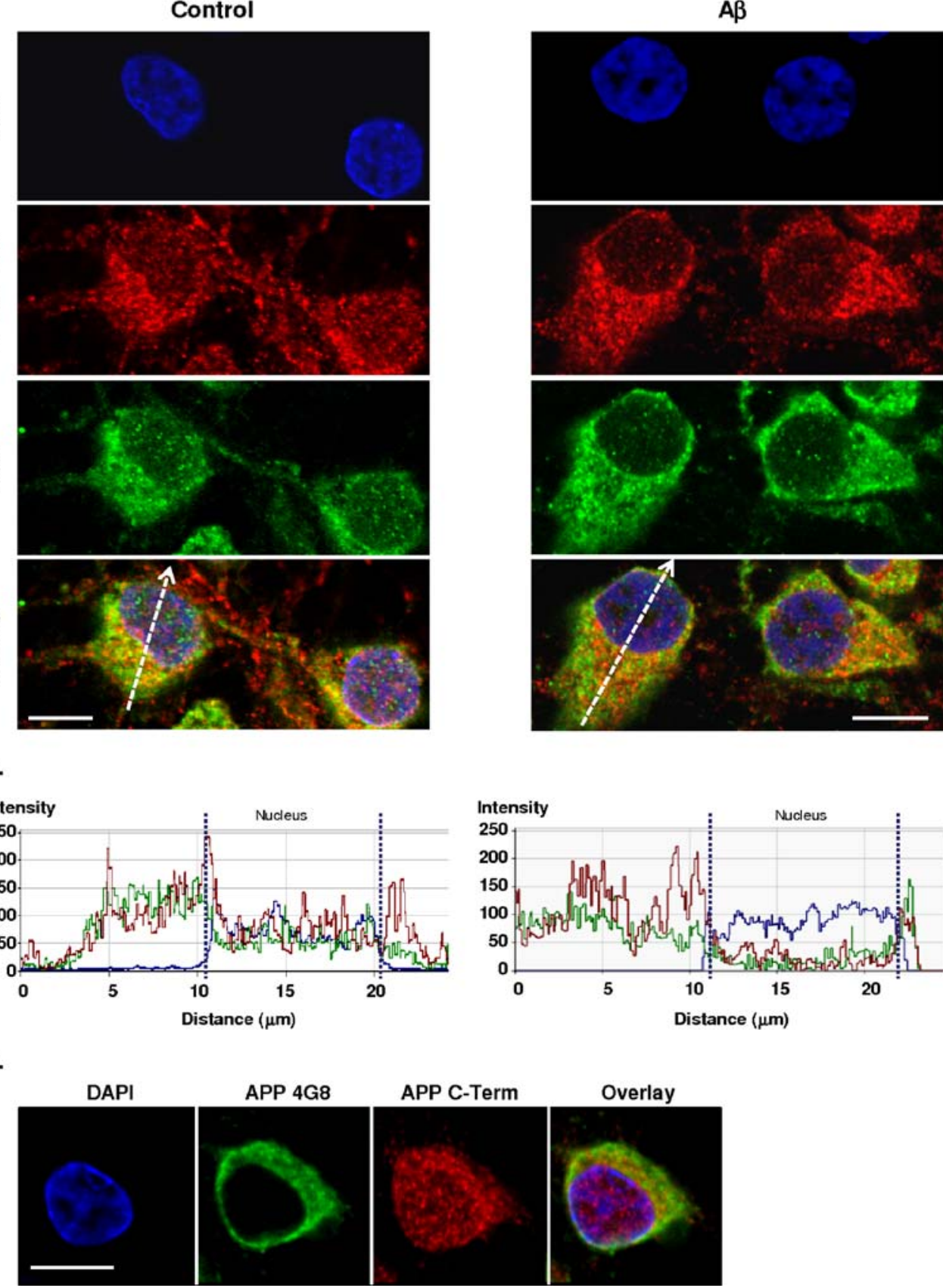

activity did not yield any significant alteration (data not shown), suggesting that CTF cleavage by $\gamma$-secretase activity per se was not hindered. An accumulation of amyloidogenic APP CTFs in response to $A \beta_{1-42}$ exposure was previously observed by Yang et al. (1995) in APP transfected HEK293 cells. In neuronally derived cells, $\gamma$-secretase cleavage was described to occur at the plasma membrane and/or early endosomes (Kaether et al. 2006). Thus, the neuronal CTF increase observed (Fig. 2b) probably reflects a block in the transport to plasma membrane and a subsequent decrease in proteolytic cleavage of CTFs. This correlates well with our findings of isAPP retention within cytoskeleton-associated vesicular-like structures (Henriques et al. 2009). Hence, increased accumulation of CTFs also correlates with decreased AICD production.

AICD has been described as an APP nuclear signal peptide that can form a transcriptional active complex with Fe65 (Cao and Sudhof 2001). AICD-containing complexes were reported to induce transcriptional activation of several genes, including APP itself and GSK3 $\beta$ (Kim et al. 2003; von Rotz et al. 2004; Ryan and Pimplikar 2005). Thus, increased CTFs and concomitant decreased AICD levels would predict decreases in the AICD nuclear pool and signaling. This is consistent with the observed decrease in 
Table 1 AICD and Fe65 nuclear targeting and co-localization in response to A $\beta$

\begin{tabular}{|c|c|c|c|c|c|c|}
\hline & \multicolumn{3}{|c|}{ Nuclear targeting as a $\%$ of total population } & \multicolumn{3}{|c|}{$\%$ of each protein co-localizing to the complex in the nucleus } \\
\hline & $\mathrm{C}$ & $\mathrm{A} \beta$ & $\% \operatorname{Dec}+\mathrm{A} \beta$ & $\mathrm{C}$ & $\mathrm{A} \beta$ & $\% \operatorname{Dec}+\mathrm{A} \beta$ \\
\hline AICD & $46 \pm 3.0$ & $27 \pm 1.7$ & 42 & $33 \pm 2.0$ & $21 \pm 1.9$ & 36 \\
\hline Fe65 & $36 \pm 2.0$ & $16 \pm 1.4$ & 56 & $22 \pm 1.1$ & $20 \pm 1.6$ & 10 \\
\hline
\end{tabular}

Analysis was carried out using a Zeiss confocal microscope co-localization software. The percentage of nuclear AICD and Fe65 immunopositive pixels were determined relative to the total neuronal cell populations, excluding dendrites and axons (nuclear targeting as a percentage of the total population). The "\% of each protein co-localizing to the complex in the nucleus" represents the percentage of each protein (AICD or Fe65) colocalizing to the other and relative to its total nuclear population. "\% Dec $+\mathrm{A} \beta$ " is the percentage decrease upon $\mathrm{A} \beta$ addition. Data are presented as mean \pm SEM of 40 analyzed cells

APP expression levels (Fig. 1a) and a significant decrease in total GSK3 levels (Fig. 2c). Direct measurements of AICD were not possible given that the endogenous levels in primary cultures are difficult to detect.

\section{A $\beta$ Decreases Nuclear Targeting of APP C-Terminal Proteolytic Products and Fe65}

Our observation that $A \beta$ increased APP CTF levels and decreased APP transcriptional activation and GSK3 expression levels (Figs. 1 and 2) is consistent with a decrease in AICD production and subsequent decreased transactivation of AICD downstream genes. Hence, we focused on AICD/ Fe65 nuclear targeting and complex formation. The nuclear targeting of APP C-terminal proteolytic products was clearly hindered in the presence of $\mathrm{A} \beta$ (Fig. 3a, Texas Red staining). The APP C-terminal peptides detected in the nucleus and positive for the APP C-terminal antibody were negative for the $4 \mathrm{G} 8$ antibody, reinforcing the identity of the nuclear targeted APP C-terminal peptides as AICD proteolytic fragments (Fig. 3c). Under our experimental conditions, $A \beta$ exposure decreased not only the intensity of nuclear APP C-terminal punctuate immunoreactivity (Fig. 3a, Texas Red staining) but also Fe65 nuclear intensity and targeting (Fig. 3a, green fluorescein staining). As a consequence, the co-localization of nuclear AICDFe65 was also compromised. Confocal profiling demonstrated that both proteins dramatically decreased in the nucleus (DAPI-positive organelle) following $A \beta$ treatment (Fig. 3b). Hence, the blue trace (denotes the nucleus) is sustained with $A \beta$ exposure, whereas the red and green traces for AICD and Fe65, respectively, drop similarly. Of note, this analysis was carried out in non-apoptotic cells, as denoted by nucleus morphology (DAPI staining).

Detailed co-localization studies of AICD and Fe65 immunoreactivity in the nucleus using Zeiss confocal colocalization software (Table 1) also confirmed $A \beta$-induced alterations in the nuclear targeting of both proteins. The

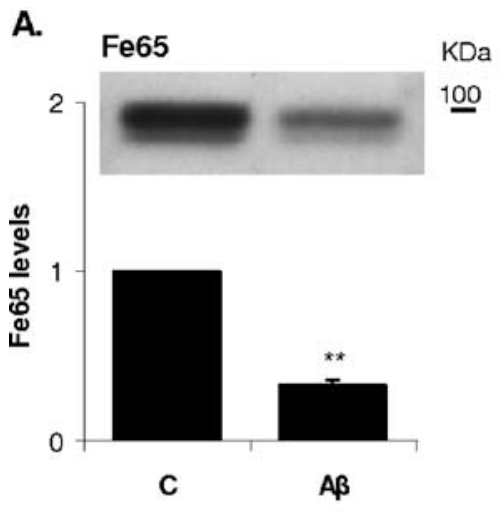

B.

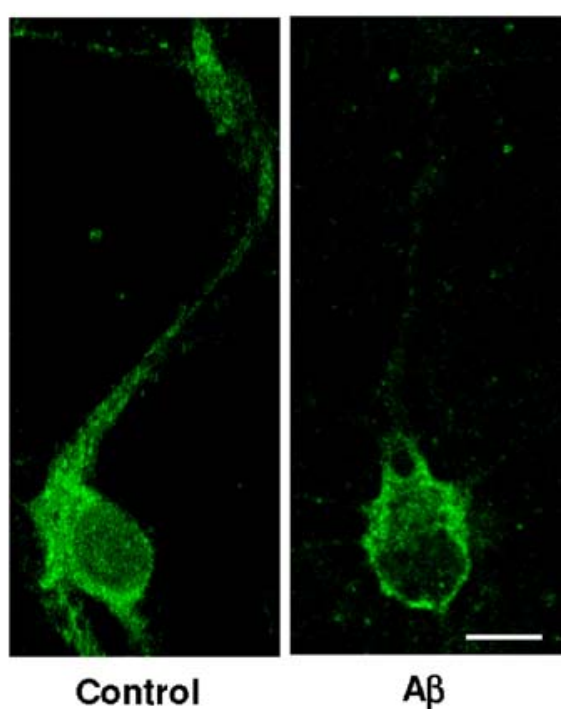

Figure $4 \mathrm{~A} \beta$ effect on Fe65. Fe65 intracellular levels were evaluated using both immunoblotting (a) and immunofluorescence (b). Fe65 immunoreactivity was analyzed by confocal microscopy at a focus

plane above the nucleus and just below the plasma membrane. ${ }^{* *} P<$ 0.01 , significantly different from control using Dunnett post hoc test. $C$ control, $A \beta \mathrm{A} \beta$ treatment for $24 \mathrm{~h}$ 
percentage of both AICD and Fe65 positive pixels present in the nucleus, relative to the total neuronal soma population, showed a decrease of $42 \%$ and $56 \%$, respectively. Focusing on the nuclear population alone, we were able to determine that the AICD nuclear population colocalizing with Fe65 dropped from 33\% to 21\% upon addition of $\mathrm{A} \beta$, which represents a $36 \%$ decrease. There was no significant difference in the percentage of the Fe65 nuclear population that co-localized with AICD $(22 \%$ and $20 \%$ ). Additionally we determined that the AICD population, as a percentage of the total APP C-terminal immunoreactivity, co-localizing to $\mathrm{Fe} 65$ in the nucleus decreased from $\sim 15 \%$ (33\% of the $46 \%$ of the nuclear targeted population, see Table 1) to $\sim 5 \%$ (21\% of $27 \%$ ) upon exposure to $\mathrm{A} \beta$. Likewise, we determined the values for Fe65, and the decrease was from $\sim 7 \%$ (22\% of $36 \%)$ to $\sim 4 \%$ (20\% of $16 \%$ ).

Given that the nuclear abundance of both AICD and Fe65 were affected, we also tested the latter directly by immunoblotting and immunofluorescence. Our data showed a clear decrease in Fe65 intracellular levels in response to $A \beta$ (Fig. 4a). This was also evident by confocal microscopy at a focus plane above the nucleus and just below the plasma membrane where Fe65 immunoreactivity decreased overall, being particularly visible along neurites (Fig. 4b).

Taken together, our results suggest that $A \beta$ is affecting AICD production, its nuclear translocation, and nuclear complex formation with Fe65 whose nuclear targeting is itself decreased. A decrease in AICD production and in the formation of $\mathrm{AICD} / \mathrm{Fe} 65$ transactivation complexes potentially leads to altered APP nuclear signaling in the presence of $A \beta$, leading to impaired gene transcriptional activation.

In summary, we propose that $\mathrm{A} \beta$ leads to reduced $A P P$ expression and consequentially diminished $A \beta$ production, which is important for cells exposed to an $A \beta$-saturated environment. It is attractive to postulate that the aforementioned mechanisms congregate to reduce intracellular accumulation of $A \beta$ and that exogenous $A \beta$ appears to induce a set of concerted cellular responses to prevent its own production, including reduced AICD/Fe65 nuclear targeting. We hypothesize that a physiologically relevant negative feedback mechanism may be operating, tightly coordinating the levels of APP expression and AICD and A $\beta$ production. Further, as APP CTF levels progressively decrease in AD (Sergeant et al. 2002), this feedback mechanism may be lost with the progression of the disease. This would be a physiologically relevant process given that neurons exhibit higher levels of $\mathrm{A} \beta$ production. Nonetheless, we cannot exclude that non-physiological $A \beta$ concentrations may trigger neuronal stress mechanisms which may in turn affect APP metabolism and $\mathrm{A} \beta$ production; future research will address this question.
Acknowledgments This study is supported by the European Union VI Framework Program (Project cNeupro), Fundação para a Ciência e Tecnologia (FCT) of the Portuguese Ministry of Science and Technology (POCTI/NSE/40682, POCI/BIA-BCM/58469, REEQ/ 1023/BIO/2005), and Centro de Biologia Celular, Universidade de Aveiro. AGH and SIV were recipients of a Ph.D (BD/16071) and post-doctoral (BPD/19515) fellowships, respectively, from FCT.

\section{References}

Allinson, T. M., Parkin, E. T., Turner, A. J., \& Hooper, N. M. (2003). ADAMs family members as amyloid precursor protein alphasecretases. Journal of Neuroscience Research, 74, 342-352. doi:10.1002/jnr.10737.

Amador, F. C., Henriques, A. G., da Cruz, E. S. O. A., \& da Cruz, E. S. E. F. (2004). Monitoring protein phosphatase 1 isoform levels as a marker for cellular stress. Neurotoxicology and Teratology, 26, 387-395. doi:10.1016/j.ntt.2003.12.007.

Ando, K., Iijima, K. I., Elliott, J. I., Kirino, Y., \& Suzuki, T. (2001). Phosphorylation-dependent regulation of the interaction of amyloid precursor protein with $\mathrm{Fe} 65$ affects the production of beta-amyloid. The Journal of Biological Chemistry, 276, 4035340361. doi:10.1074/jbc.M106460200.

Baek, S. H., Ohgi, K. A., Rose, D. W., Koo, E. H., Glass, C. K., \& Rosenfeld, M. G. (2002). Exchange of N-CoR corepressor and Tip60 coactivator complexes links gene expression by NFkappaB and beta-amyloid precursor protein. Cell, 110, 55-67. doi:10.1016/S0092-8674(02)00809-7.

Brewer, G. J., Torricelli, J. R., Evege, E. K., \& Price, P. J. (1993). Optimized survival of hippocampal neurons in B27-supplemented Neurobasal, a new serum-free medium combination. Journal of Neuroscience Research, 35, 567-576. doi:10.1002/jnr.490350513.

Buxbaum, J. D., Liu, K. N., Luo, Y., Slack, J. L., Stocking, K. L., Peschon, J. J., et al. (1998). Evidence that tumor necrosis factor alpha converting enzyme is involved in regulated alpha-secretase cleavage of the Alzheimer amyloid protein precursor. The Journal of Biological Chemistry, 273, 27765-27767. doi:10.1074/jbc. 273.43 .27765 .

Cao, X., \& Sudhof, T. C. (2001). A transcriptionally [correction of transcriptively] active complex of APP with Fe65 and histone acetyltransferase Tip60. Science, 293, 115-120. doi:10.1126/ science. 1058783.

Capell, A., Beher, D., Prokop, S., Steiner, H., Kaether, C., Shearman, M. S., et al. (2005). Gamma-secretase complex assembly within the early secretory pathway. The Journal of Biological Chemistry, 280, 6471-6478. doi:10.1074/jbc.M409106200.

Carlson, C. D., Czilli, D. L., \& Gitter, B. D. (2000). Regulation of amyloid precursor protein processing by Abeta in human glioma cells. Neurobiology of Aging, 21, 747-756. doi:10.1016/S01974580(00)00172-X.

da Cruz e Silva, O. A., Fardilha, M., Henriques, A. G., Rebelo, S., Vieira, S., \& da Cruz e Silva, E. F. (2004). Signal transduction therapeutics: relevance for Alzheimer's disease. Journal of Molecular Neuroscience, 23, 123-142. doi:10.1385/JMN:23:1-2:123.

da Cruz e Silva, O., Rebelo, S., Vieira, S., Gandy, S., da Cruz e Silva, E. F., \& Greengard, P. F. (2009). Enhanced generation of Alzheimer's Abeta following chronic exposure to phorbol ester correlates with differential effects on alpha and epsilon isozymes of protein kinase C. Journal of Neurochemistry, 108, 309-330.

Davis-Salinas, J., Saporito-Irwin, S. M., Cotman, C. W., \& Van Nostrand, W. E. (1995). Amyloid beta-protein induces its own production in cultured degenerating cerebrovascular smooth muscle cells. Journal of Neurochemistry, 65, 931-934. 
Esler, W. P., Kimberly, W. T., Ostaszewski, B. L., Ye, W., Diehl, T. S., Selkoe, D. J., et al. (2002). Activity-dependent isolation of the presenilin-gamma-secretase complex reveals nicastrin and a gamma substrate. Proceedings of the National Academy of Sciences of the United States of America, 99, 2720-2725. doi:10.1073/pnas.052436599.

Haass, C., Schlossmacher, M. G., Hung, A. Y., Vigo-Pelfrey, C., Mellon, A., Ostaszewski, B. L., et al. (1992). Amyloid betapeptide is produced by cultured cells during normal metabolism. Nature, 359, 322-325. doi:10.1038/359322a0.

Haass, C., Hung, A. Y., Schlossmacher, M. G., Oltersdorf, T., Teplow, D. B., \& Selkoe, D. J. (1993). Normal cellular processing of the beta-amyloid precursor protein results in the secretion of the amyloid beta peptide and related molecules. Annals of the New York Academy of Sciences, 695, 109-116. doi:10.1111/j.17496632.1993.tb23037.x.

Henriques, A. G., Vieira, S. I., Rebelo, S., Domingues, S. C., da Cruz e Silva, E. F., \& da Cruz e Silva, O. A. (2007). Isoform specific amyloid-beta protein precursor metabolism. Journal of Alzheimer's Disease, 11, 85-95.

Henriques, A., Vieira, S. I., Crespo-López, E., Oliveira, M., Da Cruz e Silva, E. F., \& Da Cruz e Silva, O. A. B. (2009) Intracellular sAPPalpha retention in response to Abeta is mapped to cytoskeleton associated structure. Journal of Neuroscience Research, 87(6), 1449-1461.

Kaether, C., Schmitt, S., Willem, M., \& Haass, C. (2006). Amyloid precursor protein and Notch intracellular domains are generated after transport of their precursors to the cell surface. Traffic (Copenhagen, Denmark), 7, 408-415. doi:10.1111/j.1600-0854.2006.00396.x.

Kim, H. S., Kim, E. M., Lee, J. P., Park, C. H., Kim, S., Seo, J. H., et al. (2003). C-terminal fragments of amyloid precursor protein exert neurotoxicity by inducing glycogen synthase kinase-3beta expression. The FASEB Journal, 17, 1951-1953.

Kimberly, W. T., Zheng, J. B., Guenette, S. Y., \& Selkoe, D. J. (2001). The intracellular domain of the beta-amyloid precursor protein is stabilized by Fe65 and translocates to the nucleus in a notch-like manner. The Journal of Biological Chemistry, 276, 40288-40292.

Le, W., Xie, W. J., Nyormoi, O., Ho, B. K., Smith, R. G., \& Appel, S. H. (1995). Beta-amyloid1-40 increases expression of betaamyloid precursor protein in neuronal hybrid cells. Journal of Neurochemistry, 65, 2373-2376.

Lee, S. F., Shah, S., Li, H., Yu, C., Han, W., \& Yu, G. (2002). Mammalian APH-1 interacts with presenilin and nicastrin and is required for intramembrane proteolysis of amyloid-beta precursor protein and Notch. The Journal of Biological Chemistry, 277, 45013-45019. doi:10.1074/jbc.M208164200.

Li, Y. M., Lai, M. T., Xu, M., Huang, Q., DiMuzio-Mower, J., Sardana, M. K., et al. (2000). Presenilin 1 is linked with gammasecretase activity in the detergent solubilized state. Proceedings of the National Academy of Sciences of the United States of America, 97, 6138-6143. doi:10.1073/pnas.110126897.

Minopoli, G., de Candia, P., Bonetti, A., Faraonio, R., Zambrano, N., \& Russo, T. (2001). The beta-amyloid precursor protein functions as a cytosolic anchoring site that prevents Fe65 nuclear translocation. The Journal of Biological Chemistry, 276, 65456550. doi:10.1074/jbc.M007340200.

Moreno-Flores, M. T., Salinero, O., \& Wandosell, F. (1998). BetaA amyloid peptide (25-35) induced APP expression in cultured astrocytes. Journal of Neuroscience Research, 52, 661-671. doi:10.1002/(SICI) 1097-4547(19980615)52:6<661::AIDJNR5>3.0.CO;2-6.

Pardossi-Piquard, R., Petit, A., Kawarai, T., Sunyach, C., Alves da Costa, C., Vincent, B., et al. (2005). Presenilin-dependent transcriptional control of the Abeta-degrading enzyme neprilysin by intracellular domains of betaAPP and APLP. Neuron, 46, 541-554. doi:10.1016/j.neuron.2005.04.008.
Rebelo, S., Vieira, S. I., Esselmann, H., Wiltfang, J., da Cruz e Silva, E. F., $\&$ da Cruz e Silva, O. A. (2007). Tyr687 dependent APP endocytosis and Abeta production. Journal of Molecular Neuroscience, 32, 1-8. doi:10.1007/s12031-007-0001-z.

Ryan, K. A., \& Pimplikar, S. W. (2005). Activation of GSK-3 and phosphorylation of CRMP2 in transgenic mice expressing APP intracellular domain. The Journal of Cell Biology, 171, 327-335. doi: $10.1083 /$ jcb. 200505078 .

Sabo, S. L., Lanier, L. M., Ikin, A. F., Khorkova, O., Sahasrabudhe, S., Greengard, P., et al. (1999). Regulation of beta-amyloid secretion by FE65, an amyloid protein precursor-binding protein. The Journal of Biological Chemistry, 274, 7952-7957. doi:10.1074/jbc.274.12.7952.

Sastre, M., Steiner, H., Fuchs, K., Capell, A., Multhaup, G., Condron, M. M., et al. (2001). Presenilin-dependent gamma-secretase processing of beta-amyloid precursor protein at a site corresponding to the S3 cleavage of Notch. EMBO Reports, 2, 835-841. doi:10.1093/embo-reports/kve180.

Schmitt, T. L., Steiner, E., Trieb, K., \& Grubeck-Loebenstein, B. (1997). Amyloid beta-protein(25-35) increases cellular APP and inhibits the secretion of APPs in human extraneuronal cells. Experimental Cell Research, 234, 336-340. doi:10.1006/ excr.1997.3606

Selkoe, D. J. (1993). Physiological production of the beta-amyloid protein and the mechanism of Alzheimer's disease. Trends in Neurosciences, 16, 403-409. doi:10.1016/0166-2236(93)90008-A.

Sergeant, N., David, J. P., Champain, D., Ghestem, A., Wattez, A., \& Delacourte, A. (2002). Progressive decrease of amyloid precursor protein carboxy terminal fragments (APP-CTFs), associated with tau pathology stages, in Alzheimer's disease. Journal of Neurochemistry, 81, 663-672. doi:10.1046/j.1471-4159.2002.00901.x.

Sisodia, S. S. (1992). Beta-amyloid precursor protein cleavage by a membrane-bound protease. Proceedings of the National Academy of Sciences of the United States of America, 89, 6075-6079. doi:10.1073/pnas.89.13.6075.

Vassar, R., Bennett, B. D., Babu-Khan, S., Kahn, S., Mendiaz, E. A., Denis, P., et al. (1999). Beta-secretase cleavage of Alzheimer's amyloid precursor protein by the transmembrane aspartic protease BACE. Science, 286, 735-741. doi:10.1126/science.286. 5440.735.

von Rotz, R. C., Kohli, B. M., Bosset, J., Meier, M., Suzuki, T., Nitsch, R. M., et al. (2004). The APP intracellular domain forms nuclear multiprotein complexes and regulates the transcription of its own precursor. Journal of Cell Science, 117, 4435-4448. doi: $10.1242 /$ jes. 01323 .

Walsh, D. M., Fadeeva, J. V., LaVoie, M. J., Paliga, K., Eggert, S., Kimberly, W. T., et al. (2003). Gamma-secretase cleavage and binding to FE65 regulate the nuclear translocation of the intracellular C-terminal domain (ICD) of the APP family of proteins. Biochemistry, 42, 6664-6673. doi:10.1021/bi027375c.

Xie, Z., Dong, Y., Maeda, U., Xia, W., \& Tanzi, R. E. (2007). RNA interference silencing of the adaptor molecules ShcC and Fe65 differentially affect amyloid precursor protein processing and Abeta generation. The Journal of Biological Chemistry, 282, 4318-4325. doi:10.1074/jbc.M609293200.

Yan, R., Han, P., Miao, H., Greengard, P., \& Xu, H. (2001). The transmembrane domain of the Alzheimer's beta-secretase (BACE1) determines its late Golgi localization and access to beta-amyloid precursor protein (APP) substrate. The Journal of Biological Chemistry, 276, 36788-36796. doi:10.1074/jbc.M104350200.

Yang, A. J., Knauer, M., Burdick, D. A., \& Glabe, C. (1995). Intracellular A beta 1-42 aggregates stimulate the accumulation of stable, insoluble amyloidogenic fragments of the amyloid precursor protein in transfected cells. The Journal of Biological Chemistry, 270, 14786-14792. doi:10.1074/ jbc.270.24.14786. 